\title{
La familia en la sociedad de hoy. \\ Vivencias de venezolanos de clase media
}

\section{The family in today's society. The experience of the Venezuelan middle class}

\author{
Leonor Mora Salas \\ Instituto de Psicología - Universidad Central de Venezuela \\ leonorm@movistar.net.ve
}

\begin{abstract}
Resumen
En este trabajo discuto los modos de interpretación que emplean venezolanos de clase media respecto a su familia $y$, el origen de los significados compartidos entre los miembros del grupo familiar. Método: realicé un estudio cualitativo con entrevistas individuales en cinco familias del estrato socioeconómico medio. Resultados: los entrevistados narran sus experiencias familiares y de relación con el espacio público construyendo un discurso donde la trama de sus vidas se encuentra con la de los otros familiares; su modo de vida está íntimamente relacionado con tradiciones y costumbres de la familia de origen y de la actual, con el intercambio y los estilos de relación que establecen sus miembros entre sí. Conclusión: el estudio indica que las personas buscan adaptar la familia al tiempo actual y a las exigencias del medio, sin desvirtuar por ello sus convicciones y principios, hecho que garantizaría su permanencia en el tiempo.
\end{abstract}

Palabras clave: familia y sociedad, familias de clase media, vida familiar, significados

\begin{abstract}
The present study investigates how the Venezuelan middle class understands the family, and identifies the origin of meanings shared among family members. Individual interviews were conducted with members of five middle class families. In telling of their family experiences, and their relationship with the public sphere, interviewees intertwined the narrative of their life with that of other family members. They intimately connected their lifestyles to the customs and traditions of their childhood and their current family. This study shows that people try to adapt family life to current contingencies, without compromising their convictions and principles. This will guarantee the family's stable survival over time.Keywords: family and society, middle class families, family life, meanings.
\end{abstract}

Keywords: family and society, middle class families, family life, meanings 


\section{Introducción ${ }^{1}$}

El estudio de la familia en los inicios del siglo XXI es una tarea retadora y de compromiso, especialmente, para quienes desde la Psicología del Desarrollo Humano pretendemos comprender su estado actual. Ello supone saber que transitamos por un terreno sin heredad específica, cuyo estudio representa un lugar común con fronteras que se desdibujan entre los diferentes campos de conocimiento social. Realizar una aproximación inicial a las vivencias de venezolanos sobre la familia a partir de las narraciones de sus miembros, me permitirá avanzar en la construcción de algunas propuestas concretas que contribuyan a responder a situaciones vividas por las familias en lo cotidiano. En este trabajo intento responder a las interrogantes siguientes: ¿cuál es el sentido que tiene la familia para venezolanos de estrato socioeconómico medio?, ¿cómo se construyen las formas de interpretar el mundo en el contexto de la familia? Una primera respuesta a estas interrogantes podría sugerir líneas de investigación para ser abordadas críticamente en lo subsiguiente.

Los contenidos del artículo los he organizado en cuatro secciones: la primera recoge algunos elementos de carácter conceptual y empírico para situar la línea teórica en la cual se inscribe el estudio; la segunda describe elementos de orden metodológico y del procedimiento efectuado; la tercera presenta la discusión de los resultados en dos categorías teóricas; la última incluye las conclusiones.

\section{Contexto conceptual}

La familia actual se caracteriza por su naturaleza plural, la variación de su estructura, temporalidad de las uniones y singularidad de los roles que desempeñan sus miembros en tanto padres, madres, hijos $\mathrm{u}$ otros parientes. Hoy la familia se muestra diferente, variable, compleja, pero especialmente, singular. Cualidad que se expresa en sus «contenidos, delimitaciones, normas, moral y posibilidades ...» (Ulrich Beck y Elizabeth Beck, 2001, p. 20). Revisar su presente concreto a través de aspectos referidos a su cotidianidad y a la dinámica de sus relaciones internas y con el espacio público es el propósito de este apartado.

\section{Familia, cotidianidad familiar y relación con el espacio público}

La familia entendida como la «unión de personas que comparten un proyecto vital de existencia en común que se quiere duradero...» (Jesús Palacios y María Rodrigo, 2001, p. 33), supone el desarrollo de vínculos de confianza, intercambio e interdependencia entre sus miembros, el afianzamiento de la pertenencia grupal, así como una evolución tanto en el plano individual, como en el grupal.

Dentro de la psicología, la tradición nos ha permitido comprender a la familia como el contexto primordial de desarrollo y formación de la persona en tanto le provee de un «marco ideal para socializarse» (Esperanza Ceballos y María Rodrigo, 2001). Este conjunto de normas, valores y modos de actuar, facilitarán en la persona su adaptación social y la continuidad de su desarrollo personal.

\footnotetext{
${ }^{1}$ El estudio es parte del proyecto Género y vida familiar: un estudio de significados. Proyecto financiado por el Consejo de Desarrollo Científico y Humanístico de la Universidad Central de Venezuela. Responsable del proyecto: Cristina Otálora Montenegro; Co-investigadoras: Ileana Recagno-Puente y Leonor Mora Salas.
} 
De allí que la familia logra ubicarse en el referente más importante para sus miembros y para el grupo social al cual se pertenece. En la familia se «genera y transmite la forma básica del valor moral: las maneras de vinculación social, que es lo que sostiene lo comunitario y los imaginarios -el sistema de representación de la cultura...» (Fernando Vidal, 2003, p. 357). A su vez, como consecuencia de la influencia cultural, en la familia aparecen patrones comunes relativos a la comunicación intrafamiliar, la educación de los hijos y el papel que desarrollan el padre y la madre.

En razón de lo anterior es necesario distinguir las características y particularidades genéricas que inciden sobre el estatus y el rol de los diferentes miembros de la familia. Al respecto se puede señalar que el rol femenino se muestra dinámico, participativo y adaptable a las diferentes situaciones de la vida actual. El rol masculino avanza sobre la adquisición de otras funciones de cuidado y educación de los hijos que antes no desempeñaba. La presencia de los hijos la determina el consenso alcanzado por la pareja, en función de sus necesidades psicológicas y emocionales. Las prácticas que ocurren dentro del hogar muestran una re-configuración que plantea, desde la pareja, el tránsito hacia una «democratización» (Anthony Guiddens, 2000; Vidal, 2003) de las relaciones.

El proceso de transición que se vive en la actualidad (Elizabeth Beck, 2003; Beck y Beck, 2001; Dariela Sharim, 2005), permite distinguir una mezcla contradictoria de lo tradicional y de nuevas expectativas frente a la familia, la identidad y los roles de género, también, una mayor apertura en la relación de la familia con otras instituciones del espacio público. La participación de la mujer en el medio laboral, el acceso de los diferentes miembros de la familia a niveles superiores en el sistema educativo, los cambios que acontecen en las relaciones entre hombres y mujeres (Sharim, 2005; Mara Viveros, 2000), son los signos claves que han repercutido en un nivel de participación social, laboral y política otrora inexistente, así como en una mayor visibilización de la familia y de su cotidianidad.

En el macro contexto donde ocurre la vida de la familia es posible encontrar serias amenazas de carácter global no sólo para ella sino para la sociedad en su conjunto, aunque «... las denominadas "amenazas globales" han conducido a un mundo en el que se ha erosionado la base de la lógica establecida del riesgo y en el que prevalecen peligros de difícil gestión en lugar de riesgos cuantificables....» (Ulrich, Beck, 2002, p. 4). Los riesgos, en tanto manifestaciones de lo real y productos de la construcción social, representan «... híbridos hechos-por-humanos, que incluyen y combinan política, ética, matemáticas, medios de comunicación de masas, tecnología, definiciones y percepciones culturales» (Ulrich, Beck, 2000, p. 19). Es un hecho que la globalización y la perdurabilidad hacen que tales riesgos representen un futuro amenazante que pauta las acciones del presente, frente a ello existe la «... utopía de una modernidad responsable, la utopía de otra modernidad, muchas modernidades por inventar y por experimentar en diferentes culturas y partes del globo». (Beck, 2000, p. 20).

\section{La familia venezolana de clase media: contexto cultural y económico}

Una definición de la familia venezolana de clase media podemos hacerla a partir de la consideración de las dimensiones cultural y económica. En la dimensión cultural es preciso destacar la evolución experimentada por la familia y el alejamiento de los patrones tradicionales relativos a su estructura y dinámica. Las familias de clase media tienen por lo menos a uno de sus miembros con estudios de nivel universitario. En el caso de familias con madres profesionales y laboralmente activas, se produce una modificación en la organización familiar con repercusiones en una nueva manera de 
asumir la pareja y la crianza de los hijos (Alex Capriles, 2000; Mikel De Viana, 2000; Ileana RecagnoPuente, 2002). Estos hechos han traído como consecuencia una nueva configuración de la familia (Recagno-Puente, 2002) que se expresa en: parejas sin hijos, madres solas como opción de vida, parejas reconstituidas, padres solos con sus hijos y sin pareja estable, entre otras estructuras, en donde los roles tradicionales de hombres y mujeres se cuestionan y en algunos casos entran en conflicto.

Las diversas situaciones que afrontan mujeres y hombres de clase media, quienes deciden optar por una u otra forma de familia, están mediadas por lo que la cultura les ofrece: la socialización transmitida a través de su familia de origen, la obtención de niveles altos de escolaridad, la participación en el mundo del trabajo, el acceso a un nivel de vida con comodidades, los niveles de reflexión alcanzados para racionalizar y entender procesos complejos y difíciles como la separación o la muerte.

En la dimensión económica, las familias pertenecientes a la clase media en Venezuela se distinguen por tener ingresos económicos estables, profesión y niveles de escolaridad elevados -tanto del padre como de la madre- vivienda en condiciones buenas y/o superiores, características que les permiten organizarse de una manera más coherente con un estado de bienestar. Estas características se establecen a través del método de estratificación social Graffar-Méndez Castellano (Fundacredesa 1996; 2001), según el cual, la clase media se representa en los estratos II y III. La estratificación se realiza a partir de las variables profesión del jefe de familia; nivel de instrucción de la madre; principal fuente de ingreso de la familia; condiciones de alojamiento (Fundacredesa, 2001).

A las familias del estrato III se les atribuyen los rasgos siguientes: un nivel de escolaridad elevado, con ingresos que corresponden a sueldos mensuales; no se reportan ganancias y honorarios profesionales, lo cual permite suponer un deterioro en el ingreso de los profesionales que ejercen de manera independiente. Las condiciones habitacionales son inferiores a las existentes en décadas anteriores y se encuentran amenazadas por el hacinamiento y la promiscuidad, a consecuencia de la disminución del poder adquisitivo. Los servicios públicos de salud son requeridos por personas de este estrato, aunque el acceso se ve limitado por el deterioro progresivo de su infraestructura y dotación. La educación de los hijos se realiza a través de los servicios públicos, a pesar de la insuficiencia de los planteles y la mala dotación que estos presentan. En lo relativo a la participación social organizada se valora la importancia de la cogestión entre comunidad, gobierno y empresa privada a los fines de obtener la solución de los problemas que los afectan (Fundacredesa, 2001).

Otras cualidades de familias venezolanas de clase media las proporciona Sarah Catalán (2004), cuando destaca su estilo de vida y el equilibrio que logran de la combinación de funciones, al hacer adecuaciones en el plano individual y en el familiar. Este esfuerzo pareciera ser mayor para el caso de las mujeres quienes conservan la responsabilidad primaria del hogar y requieren importantes niveles de organización para el desempeño eficiente de las diferentes funciones que cumplen dentro y fuera de él. El hombre logra acomodos más prácticos para ejercer su rol de padre, si se quiere mucho más activo. En general, las parejas son protagonistas de un período sociohistórico en el cual los roles femenino y masculino están sujetos a una constante reevaluación y redefinición. Dentro de la familia, hombres y mujeres participan en la construcción de una nueva identidad de género que pretende ser más igualitaria. 


\section{Vivencias y significados}

Las vivencias que forman parte de nuestra vida cotidiana no son necesariamente el objeto de nuestros interrogantes y cuestionamientos más comunes, sólo recurrimos a ellas cuando nos proponemos un análisis crítico de las acciones que hacen parte del día a día. Dentro de cualquier contexto de desempeño habitual del ser humano, las rutinas llegan a naturalizarse desde la acción y desde el modo en que cada comunidad en particular decide significarlas. A través de su discurso las personas reflejan la consolidación del consenso, la negociación y el acuerdo sobre la naturalización de las rutinas, en otras palabras, en el discurso denotan el modo de significar sus experiencias en el mundo.

De tal forma que las historias que se construyen en el espacio colectivo representan una unidad de sentido, reflejo del tiempo en el cual se inscribe la historia... «Es como si la identidad de una persona, la forma de una vida humana concreta, el sentido de quién es y de lo que le pasa, sólo se hiciera tangible en su historia» (Jorge Larrosa, 1996, p. 28). Las historias que nos contamos además de representar la trama de vida personal, porque al contarlas interpretamos lo que significa para nosotros lo vivido, constituyen el medio posible de la comunicación y comprensión de la vida de los otros, representan un recurso para la construcción y transformación de la historia de cada uno.

El valor intrínseco de las historias está marcado por un conjunto de factores estrechamente vinculados: a) el carácter humano presente en la construcción, interpretación y representación de sí mismo que hace cada protagonista; b) la trama que conforman en su contenido las acciones e intencionalidad humana y se manifiesta en una mezcla entre lo real e imaginativo; c) el contenido cultural y subjetivo que entrañan, el cual habla a su vez de un hombre y de los hombres; d) el poder que tienen para la negociación social y para versionar el mundo desde sus épocas más remotas; e) el carácter humano que comportan las historias permite aceptar como una propiedad, también humana, el hecho de su transformación (Jerome Bruner, 1991).

La vida como «historia que se despliega» (Larrosa, 1996), adquiere la estructura de una novela que interpreta lo que somos, en tanto trama narrativa provista de sentido, tiempo, contexto, acciones y personajes. Estas narraciones comprenden en sí mismas, entre otras propiedades (Bruner, 1991): a) una secuencia de hechos que le acontecen al protagonista y a los personajes de la historia, es así que el sentido que dan a la historia el protagonista y el espectador, responde al significado global de la trama que en ella se urde, independientemente de la verdad o falsedad de los contenidos; b) una expresión de los vínculos que se establecen en la historia entre lo excepcional y lo corriente, vínculos que permiten la negociación de significados y sirven de soporte a la cultura a la vez que la recrean, pues por su carácter dramático traducen lo moralmente valorado, apropiado e incierto; c) una ocurrencia de hechos que se dan en un pasaje dual por cuanto suceden en el mundo de lo real y en la conciencia del que construye la historia.

En la interpretación de las historias narradas por otros se valora la existencia de muchos mundos posibles cuyo origen se ubica en la creación de diversos significados y realidades y, en el acuerdo que permite la construcción de nuevos significados; este acuerdo actúa, a la vez, como mecanismo regulatorio de las relaciones entre los individuos (Bruner, 1991, 1998). En esta línea cobra relevancia la interacción entre los miembros de un grupo, como medio para favorecer el intercambio y para generar asentamientos, expresiones y situaciones culturales, que no son otra cosa que espacios y áreas de pertenencia donde se comparten y negocian formas de interpretar el mundo. 


\section{Descripción del estudio}

Mi interés en el estudio se centró en profundizar en la comprensión de los modos de interpretación de la realidad, particularmente aquellos que se crean en torno a la familia de hoy, y en comprender el origen de estos significados que son compartidos por los miembros de la familia.

Desarrollé una investigación cualitativa, cuya finalidad es el estudio de la vida cotidiana desde el enfoque que le dan los propios actores (Catherine Marshall y Gretchen Rossman, 1989; Anselm Strauss y Juliet Corbin, 2002). Esta selección obedece al interés investigativo de captar el sentido que subyace a lo que se narra respecto a lo que se vive (Peter Banister; Erica Burman; lan Parker; Maye Taylor y Carol Tindall, 2004). Utilicé el estudio instrumental de casos (Robert Stake, 1999) como estrategia para abordar la diversidad de cada grupo familiar y, para profundizar en el conocimiento de cada uno de ellos.

Los grupos familiares los seleccioné atendiendo a los criterios de «heterogeneidad y accesibilidad» (Miguel Valles, 2000, p. 91). Buscando así respetar la variabilidad existente en las estructuras familiares, así como en el número y tipo de miembros que las componen. El acceso a los grupos familiares lo realicé de manera secuencial a través de contactos establecidos con mediación de colegas o de las familias previamente entrevistadas. Seleccioné los casos por cada grupo familiar a través del «muestreo de casos» (Uwe Flick, 2004, p. 75) y según los criterios de género, edad y tipo de parentesco, lo que determinó la participación de mujeres y hombres pertenecientes a grupos de edad diferentes y con roles distintos dentro de la familia. Para efectos de publicación utilicé el «muestreo para la presentación» (Flick, ob. cit.), una selección hecha de los relatos de los participantes sobre el material más ilustrativo de los conceptos trabajados en la producción teórica.

Tabla 1. Perfil, estrato socioeconómico y tipo de estructura familiar al cual pertenecen los informantes

\begin{tabular}{|c|c|c|c|}
\hline Familia & Estructura familiar & Perfil de los informantes & $\begin{array}{l}\text { Estrato } \\
\text { socioeconómico }\end{array}$ \\
\hline 1 & $\begin{array}{l}\text { Pareja unida en concubinato sin hijos } \\
\text { (unión de } 6 \text { años) }\end{array}$ & $\begin{array}{l}\text { Rosa -35 años- } \\
\text { Marcos -40 años- }\end{array}$ & II \\
\hline 2 & $\begin{array}{l}\text { Pareja homosexual con disolución por } \\
\text { muerte (unión de } 10 \text { años) }\end{array}$ & Félix -49 años- & II \\
\hline 3 & $\begin{array}{l}\text { Pareja con vínculo legal (56 años de } \\
\text { casados) }\end{array}$ & $\begin{array}{l}\text { Gabriela -75 años- } \\
\text { Paulo -84 años- }\end{array}$ & II \\
\hline 4 & $\begin{array}{l}\text { Pareja con vínculo legal sin hijos ( } 2 \text { 1/2 } \\
\text { años de casados) }\end{array}$ & $\begin{array}{l}\text { Yajaira -38 años- } \\
\text { Ramón -33 años- }\end{array}$ & III \\
\hline 5 & $\begin{array}{l}\text { Pareja reconstituida con hijos de la } \\
\text { madre (unión de } 3 \text { años) }\end{array}$ & $\begin{array}{l}\text { Laura -50 años- } \\
\text { Rubén -38 años- } \\
\text { Leonardo -14 años- }\end{array}$ & III \\
\hline
\end{tabular}


Los resultados que presento en este artículo corresponden a diez informantes, miembros de cinco familias que se ubican en los estratos socioeconómicos II y III (Fundacredesa, 2001). Las familias tienen estructuras y constitución diferentes como lo indica la Tabla 1.

En el análisis trabajé con el «método comparativo constante», a los fines de generar teoría de la información producida (Strauss y Corbin, 2002). Es decir, a través de los datos se ilustra una teoría que permite comprender los modos de interpretación de la familia y el origen de los significados que son compartidos. El uso del método contempló la actividad de análisis de la información en desarrollo paralelo con su producción, en el procedimiento desarrollé algunas de las etapas de codificación inherentes al método: codificación abierta (identificación de conceptos) y codificación axial (análisis intenso de conceptos y relación entre ellos).

\section{Análisis temático}

Los temas que discuto a continuación surgen del texto de análisis o corpus discursivo derivado de algunos contenidos presentes en las entrevistas realizadas a los participantes, las contribuciones son producto del análisis empírico que efectúo a las entrevistas. Cada uno de los temas o categorías y sus relativas divisiones en subcategorías y dimensiones (en el sentido de Strauss y Corbin, 2002) es trabajado a partir de mi interpretación sobre el discurso de los participantes. Para ilustrar las interpretaciones ofrezco una selección de los relatos que considero más demostrativos de los conceptos trabajados, utilizo para ello el «muestreo para la presentación» (Flick, 2004). En la sección de conclusiones realizo el contraste entre la producción teórica que surge de tal interpretación y los contenidos presentados en la referencia conceptual.

\section{Lo que la familia es ...}

Definir a la familia, para las personas que fueron consultadas, pasa por sostener algunas consideraciones que se manejan desde la vivencia, la valoración y la comparación. De allí que se contemplen, por una parte, aspectos propios de su vida interior como la dinámica, la interacción entre los miembros y el rol que se desempeña en la familia. Por otra parte, se establecen contrastes retrospectivos con la familia de origen y prospectivos con la nueva familia. Finalmente, se advierten atributos que relacionan a la familia con la dinámica social, el papel que cumple y el sentido que tiene para la sociedad.

La familia es descrita a partir de los contenidos de su dinámica interior y no por su estructura, número de miembros o el parentesco que existe entre ellos. Este lugar de encuentro humano además de permitir que el individuo se configure, le prepara para manifestarse en los diferentes espacios vitales. Por ende, la familia como ámbito de relaciones se coloca como un imprescindible ligado a la existencia. Los valores, reglas, afectos $y$, también, las diferencias que se conjugan en ella la determinan como una cultura, un grupo de referencia a partir del cual, cada individualidad reproduce la identidad colectiva de origen.

La familia para mí es fundamental dentro de lo que es la estructura social ... la familia es importantísima desde el punto de vista de protección, yo digo que he tenido una suerte de tener la familia que tengo ... desde muchacho siempre hubo ese empuje, tanto de mi mamá como de mi papá para que nosotros nos preparáramos, estudiáramos y, todavía, en este momento de 
adultos, que ya de cierta manera uno está haciendo su vida aparte, ellos siguen pendientes de uno, qué está haciendo, cómo lo está haciendo, si lo está haciendo (Rubén, -38ª-, f5).

Yo no me puedo imaginar una vida sin familia, aún cuando a veces uno en el límite dice «yo quisiera ser holandesa para irme de mi casa a los 17 años y hacer lo que me de la gana», pero, en la media en que creces, te das cuenta que tú eres lo que en gran media era tu familia en términos de compartir unos valores, compartir una cultura ... (Rosa, $-35^{a_{-},}$f1).

... para mi tiene un valor muy significante porque a uno le da apoyo en todo, los estudios y eso, entonces, a uno como que lo van animando y yo tengo bastante en alto a mi familia, a mi me parece muy bien (Leonardo, $-14^{\mathrm{a}}$ - f5).

El manejo conceptual que socialmente se le da a la familia permite asociarla con un conjunto de valores que no siempre la representan, por la propia evolución y por las variaciones que su vida interior y su estructura han experimentado. Es decir, la dinámica de los cambios sociales imprime sus efectos sobre la familia, al tiempo que produce en ella transformaciones. Tales variaciones no siempre hacen parte de la actualización de los discursos institucionales, como el de la escuela en el cual se define a la familia como "célula de la sociedad", utilizando una metáfora construida desde la biología. En esta definición se alude de manera directa a la familia nuclear.

Al contrastar la noción tradicional con la práctica vigente de la familia comienzan a distinguirse variantes. La esperada armonía dentro de una familia no siempre se da, al menos no como un estado permanente e invariable. Las relaciones humanas cambian, e independientemente del rumbo que tomen, influyen sobre los más pequeños y posteriormente éstos como adultos harán lo propio en la sociedad.

Debido al poder de socialización que la familia ejerce sobre sus miembros, el valor que se le atribuye pareciera superponerse al del individuo cuando se piensa en la sociedad. De tal forma que el apoyo, la educación, el afecto y las reglas, son prácticas que provienen de la familia y una vez aprendidas se reproducen en la sociedad. Por esta razón, la una permite la existencia de la otra, le sirve de fundamento, la posibilita. No es el ser humano en tanto individualidad quien define lo social, lo hace, entre otras cosas, la diversidad familiar. La familia forja lo social en tanto sus prácticas se reproducen en diferentes espacios que lo social le provee.

... no simplemente porque papá y mamá estén juntos, ya sea a través de un papel o porque decidieron vivir juntos, existe una verdadera armonía entre papá y mamá y por supuesto esa armonía permea hacia esos niñitos chiquitos y en la medida que van creciendo habrá como algo más, como un sistema único de célula, una célula única que se irán agregando al resto de la sociedad (Marcos, $-40^{a_{-},}$f1).

... aunque las familias tomen características distintas, una, porque evidentemente hay una parte de tu vida en la cual necesitas un apoyo del grupo, una educación del grupo, un entrenamiento del grupo, que si no es la familia es alguna otra cosa que se le parece pero que tiene que ver en algo y, luego, en última instancia yo no sé si viene por condición gregaria, genética, biológica o simplemente por desarrollo social, pero una vez que has crecido en una unidad de afectos o de reglas, porque al final todas vienen juntas, creo que tienes que reproducirla en muchos aspectos incluso que van mas allá de la mera familia (Rosa, $-35^{a_{-},}$f1). 
Es tal la influencia que se le atribuye a la familia en lo que significa hacer sociedad, que la formación allí recibida pauta las diferentes elecciones de vida que tendrá el adulto. Como espacio de los aprendizajes para la convivencia social, moldea el comportamiento y la manera de desenvolverte Así, mejor familia de origen, mejores bases para formar familia y para hacer mejores contribuciones sociales. Dicho de otro modo: de mi familia provengo, la formación que de ella recibo me define y desde ella me proyecto.

... la familia es como ese hilo inicial de educación o de formación que uno va teniendo como individuo, la familia te va dando, te va enseñando cómo desenvolverte en la sociedad ... (Marcos, $-40^{a_{-},}$f1).

... mientras uno venga de una mejor familia en el sentido de una familia verdaderamente funcional, uno como individuo va a ser mejor y será capaz también de formar mejores familias funcionales (Marcos, $-40^{a_{-},}$f1).

La transferencia de los aprendizajes entre un espacio (familia) y otro (sociedad), deja ver en el entorno social formaciones grupales ajustadas o no a la equidad, la libertad y la justicia. Esto nos permite distinguir a la familia como productora y transmisora de valores de convivencia, los cuales una vez trasladados al espacio externo de la familia, en algunos casos pautan las relaciones entre los hombres o contribuyen a establecerlas.

En sentido inverso, el aporte que el entorno social le ofrece a la familia está en las prácticas culturales, en las relaciones que le facilita. También los contextos particulares la determinan a través de las concepciones que maneja el grupo, los proyectos que el grupo y los miembros específicos se trazan, las acciones que realizan. De allí que el actuar humano además de estar mediado por la influencia familiar, reproduce aquello que la sociedad a través de la familia transfiere a sus miembros.

Además de proporcionar el espacio grupal del afecto y la solidaridad, la familia define la individualidad, sus miembros han de buscar el equilibrio entre los objetivos que conforman el actuar y las proyecciones de ambos. En ese sentido, el espacio familiar se asemeja a un sistema dentro del cual opera una dinámica particular que se constituye con el aporte de cada uno y las regulaciones que mutuamente se establecen.

En la familia como ámbito fundamental de los afectos, la unión y el vínculo que se producen entre sus miembros, se instituyen como emblemas de la «familia de siempre». Encuentran allí su núcleo de origen y desde allí se proyectan sobre los diferentes espacios de actuación social y desarrollo donde interviene la persona.

Ya hoy por hoy, y tengo que decirlo definitivamente como hombre gay, y es algo que comentamos mucho entre nosotros también [el grupo gay], para nosotros familia, quizás entra por supuesto la familia convencional: papá, mamá, hermanos, primos, en mi caso particular son muy cercanos con cantidad de primos y nos tratamos así pues [gesto de unidad realizado con las manos] y por donde quizás yo vaya en mi trabajo me voy encontrando con eso que yo sigo llamando mi familia: mis primos y primas y existe un vínculo muy, muy estrecho, muy cálido, muy cariñoso por esa idea de familia de siempre ... hay una sensación también de familia con esa que quizá uno llama «la familia social», posterior a todos estos vínculos que uno creó con la biológica y que también ahí se dan unos lazos muy propios de lo que sería esa otra idea de familia, en cuanto a apoyo, a participación en cosas que pueden ser en un momento dado también muy íntimas ... (Félix, -49a-, f2). 
En síntesis, la noción de familia que manejan los miembros de estos grupos consultados permite identificar singularidades determinadas por la forma de vida familiar que presenta cada agrupación y por los significados que le atribuyen sus integrantes. Ellos dan cuenta, desde sus vivencias, de los estados que experimenta la familia y cómo éstos pasan a formar parte y marcar su modo de vida particular.

\section{«Ese hogar materno ... la familia que uno tiene hasta el final»}

He dicho antes que la concepción de familia se construye a partir de las vivencias que allí se han tenido. Esto es así porque la familia de origen representa para las personas, el lugar del inicio y en algunos casos del retorno, el territorio donde el ser humano halla lo incondicional.

... la familia que uno tiene hasta el final, hasta la muerte, es el hogar donde uno se crió ese hogar materno, hasta el final yo creo que eso está ahí, yo lo siento así, esa cosa que ya uno no tiene cómo pagarle a los padres lo poco o lo mucho que le hayan dado a uno porque es algo que yo digo que ellos dejan de vivir (Rubén, $-38^{a_{-},}$f5).

La estructura que presenta la familia de origen también contribuye en su definición y valoración, influye directamente sobre las proyecciones para la familia que se pretende construir. Por ejemplo, cuando se proviene de una familia nuclear, se juzga entre sus ventajas el equilibrio que ofrece y el beneficio que representa la presencia del padre y su participación en la crianza de los hijos.

...veo que mi mamá ha sido feliz, más de los 60 años para acá, que cuando era joven que trabajó mucho, porque mi papá era un hombre noble, bueno, pero era irresponsable, como muchos hombres venezolanos y mi mamá trabajó mucho ... Mi papá dio en la familia todo eso de lo que es la sensibilidad, la creatividad, la cosa con la poesía, la lectura, la cosa intelectual ... y mi mamá ... ella era la norma, el principio, mi papá también era el principio, la moral, entonces era como un equilibrio ... (Laura, $-50^{\mathrm{a}}-$, f5).

Aunque las experiencias particulares son las que llevan a las personas a calificar a su familia positiva o negativamente, también la comparación con otras familias puede ser una forma de evaluar a la familia de procedencia. De allí que al equiparar a la familia de origen con otras familias, los criterios se establecen esencialmente sobre la base de lo que se tiene pero que no poseen las otras y de las ventajas que supone la tenencia de tales atributos. Es decir, la relación se produce en dependencia de los criterios de comparación que se adopten antes que de las características que presente el referente del contraste en sí mismo.

... a lo mejor uno de nuestros problemas es que venimos muy de la idea de que la familia es la mamá, de que el papá de uno está o no está y me ha tocado, por contactos con niños, de repente percibir de una manera muy dura cuánta falta le hace a un niño esa figura de papá, bueno, uno de repente se queja de las de uno, pero, menos mal que las tuvo ahí (Rosa, $-35^{a_{-}}$, f1).

... yo vengo de una familia de clase media y yo lo que vi fue trabajo, superación y, claro, eso es un casete para uno y un proyecto de vida ... Y yo siento que $F$. [ex pareja] siempre fue muy alejado de su familia, no tenía una noción de familia como muy clara, hoy en día lo veo, veo que le pasa a toda su familia, yo antes le echaba la culpa a él y empecé a ver en estos años de análisis, que el problema no era él, que el problema era la estructura de su familia, que eran unos viejos muy buenos, pero que no supieron como criarlos, que entre ellos son muy 
despegados, que son indolentes afectivos, lo fueron hasta con sus padres, que no estaban pendientes de lo que es un seguro, de lo que es un trabajo, cosas que para mi familia eran fundamentales (Laura, $-50^{\mathrm{a}}{ }_{-}, \mathrm{f5}$ ).

Cuando se establecen rasgos afines entre la familia y otras familias se destacan creencias, valores y principios de lealtad, respeto y equidad con el grupo. De esta forma, la familia se reafirma como unidad social homogénea $y$, en tanto tal, no excluye la existencia de diferentes nichos que representan la diversidad.

[Otras familias tienen en común con la nuestra] Valores familiares, siempre gente católica ... Sabes que hay un dicho, ellos se crían y Dios los junta... uno va buscando en los amigos las cosas que se parezcan a uno (Gabriela, - $75^{a_{-},}$f3).

... los mínimos principios nuestros ... médicos como yo y hasta trabajábamos en un hospital juntos y había una gran comunicación ... no teníamos los médicos, entre nosotros, ningún tipo de relación social con médicos que practicaban el aborto, ni los nombrábamos, es más, en la Federación Médica, en la comisión de ética, los segregábamos ... era el ambiente de la calidad en el ejercicio de la profesión, de los principios de la deontología médica (Paulo, -84ª-, f3).

En síntesis, la influencia sociocultural que recibe la familia le incorpora contenidos que ella acomoda a su propia esencia y existencia. Los estilos y costumbres inéditas pasan a ser parte de la cultura familiar, junto con las prácticas y principios tradicionales; de allí que la nueva organización es plural, discontinua, heterogénea.

\section{La nueva familia: relaciones y procesos}

La familia del porvenir marca roles y relaciones de parentesco distintas a las provistas en la familia inicial. La pareja, -relaciones y procesos de interacción-, la convivencia y los hijos definen el nuevo destino.

El sentido de la pareja: «el juego no es solo, la vida no es solo». La pareja se entiende en el sentido de la alianza que se establece entre dos personas y en la confluencia de sus vivencias. Así, la pareja representa para el individuo una compañía que contribuye a fortalecer la experiencia compartida y a enriquecer la relación, pero también es una asociación que no interfiere con el crecimiento independiente de cada uno de sus miembros.

[La pareja] ... unión de dos personas, sin decir de que género u orientación, dos personas que se acompañan, que comparten experiencias, que tienen relaciones sexuales, que se hacen cariño, que van creciendo cada una en lo suyo y después eso va enriqueciendo su vida como pareja. Muchas veces eso me lo he imaginado como dos caminos que van en paralelo algunas veces, otras veces se separan y después se vuelven a encontrar y siguen en paralelo y se vuelven a separar y a encontrar y cada encuentro va enriqueciendo y se va enriqueciendo por lo que se haya vivido también como individuo. En ese sentido, me imagino que puede ser igual hombre con hombre, hombre con mujer o mujer con mujer (Félix, -49ª-, f2).

De otra forma, la pareja es vista como complemento para la vida de las personas por un conjunto de cualidades y situaciones que se comparten. El sentido de pareja en la etapa adulta del ser humano supone la mediación del amor y, sólo, tras el intercambio que se da en la convivencia es que puede decidirse la complementariedad de la pareja. El poder funcionar juntos de manera complementaria y 
en la continuidad es lo que da el significado de pareja. Entonces, la pareja se simboliza a través de un estar unidos que se proyecta en el tiempo.

Eso te lo va diciendo el convivir rutinario con la persona ... tú vas viendo a la persona, la vas conociendo, no es rutina, sino constantemente la compañía continua. Y tú vas sacando, costumbres, estilos, experiencia ... (Ramón, -33 años-, f4).

... hay seres humanos que se enamoran pero hay una etapa en su edad adulta cuando consideran que el amor no es solamente la atracción física, sino también, si será esa persona, el complemento para llevar mi vida durante mucho tiempo... Si esa persona es la figura que puede ser el padre o la madre de mis hijos, será esa persona la que puede compartir mis gustos afines porque estamos jóvenes y queremos bailar, divertirnos. Pero, ¿será la persona que después de los años, se sienta cómodo en la casa los dos viendo una película? (Yajaira, 38 años-, f4).

En algunos casos, con respecto a la idea del complemento, la pareja se piensa como la referencia que le permite al individuo ser. En este sentido tal complementariedad es necesaria, si se quiere imprescindible, para que la persona pueda desarrollarse en su individualidad.

La pareja es la parte que te da como un enriquecimiento, una fortaleza a ti como individuo, yo sí soy de los que creo que detrás de un gran hombre hay una gran mujer y detrás de una gran mujer hay un gran hombre, pero si bien es cierto uno es uno, siempre como que necesitas el apoyo, el consejo, ese punto de referencia que siempre te va a dar la persona que está a tu lado (Marcos, $-40^{\mathrm{a}}-$, f1)

... esa parte que es vital, yo pienso que la pareja, cuando ya uno conforma pareja es esa otra parte que lo mantiene a uno vivo, se pudiera decir, algo que lo alimenta a uno y es el apoyo para seguir por la vida ... viene siendo, sí, ese ciclo natural que tenemos los seres humanos de tener una vida en pareja y también uno fue criado de alguna manera como para hacer una familia ... es el sentirse de alguna manera querido y querer a alguien, alguien que es distinto a la familia pero que hay un amor que por supuesto no es el mismo amor del hogar sino es un amor entre un hombre y una mujer que es lo que lo llena a uno (Rubén, -38 ${ }^{-}-$, f5).

Relaciones: tú, yo, nosotros. Entender y respetar al otro que forma parte de la pareja pasa por reconocer la propia individualidad y la de aquel, implica valorar el apoyo que recibe la relación al considerar los aportes que cada uno hace para su funcionamiento. El individuo preexiste a la relación, la decide, la constituye, pero en este hacer no se desdibuja a sí mismo, por el contrario, desde el reconocimiento de su unicidad contribuye con la relación, define el entendimiento con el otro y aporta a la construcción del hacer juntos.

... indudablemente hay bastante afinidad ... sí, hay muchos puntos en común, hay muchas cosas de lo que es el respeto hacia el individuo y el respeto hacia el equipo. Porque, si bien es cierto, que en un momento dado uno se une para una vida en pareja, también hay momentos... hay un punto de unión, pero existe la individualidad, y esa es una de las cosas que ha permitido que esto funcione bien. Es decir, entendemos que hay un juego en equipo y a la vez nos respetamos nuestras individualidades y principalmente nos respetamos como personas que yo creo que es una de las cosas básicas para que todo funcione (Marcos, -40 ${ }^{-}$, f1). 
[La nueva pareja] ... me ha ayudado mucho a ser menos autosuficiente, he entendido que él tiene ese mundo masculino que es importante, que hay cosas que hacen los hombres y cosas que hacemos las mujeres, que yo no puedo hacerlo todo, ha sido bien diferente, creo que he ido aprendiendo. Lo que no pude hacer en mi primer matrimonio, lo he podido hacer con esta pareja (Laura, $-50^{\mathrm{a}}-$, f5).

Una relación que se plantea entre adultos pareciera asumir como inherente una madurez propia y de la pareja. Si la unión se cifra en el complemento, ello no tendría por qué interferir en el modo de ser de cada quien, sino en la construcción de una vida juntos nutrida por los aportes de ambos en favor del vínculo.

... nosotros nos conocemos ya como adultos, no es una relación que nació de hace 20 años atrás, nosotros estamos viviendo juntos 6 años y conociéndonos ponle 6 y medio, ya nos conocimos, los dos profesionales e independientes y todos eso. No podemos pretender ahora un cambio alrededor de ella, la abnegada ama de casa que cuando yo llegue y abra la puerta me esté esperando con unas galletas así y una bandejita con un cafecito o un whiskicito ni mucho menos, eso en esencia. Sí buscamos como tener el soporte o el equilibrio de cómo llevar la casa, de cómo nos comportamos ... (Marcos, -40ª-, f1).

Cuando se sostiene la relación, la unión entre el ciclo de vida y el ciclo familiar logra consolidarse en la tercera edad, cuando hay un nuevo tiempo para la pareja y se da el encuentro reposado, el reencuentro para el balance, esta vez cargado con el valor de la experiencia, muchas veces, con el peso de la enfermedad y la mengua del bienestar. Se entra, además, en la disyuntiva del tiempo real y el tiempo posible que resulta de las postergaciones hechas por la pareja para el momento de estar nuevamente solos, cuando los hijos se van.

... nosotros medio viajábamos un poquito, yo le dejaba los muchachos a mi mamá y hacíamos un viajecito y entonces él me decía "mira cuando se casen los muchachos, nos la vamos a pasar viajando, por lo menos dos o tres veces en el año vamos a viajar, cuando se vayan y que yo esté jubilado" ... y resulta que no lo hacemos porque entonces vienen las enfermedades, yo ahora padezco de problemas, tengo artritis y, bueno, ya uno no tiene ese ánimo para andar viajando ni mucho menos ... Total que nosotros no viajamos nada. (Gabriela, -75a-, $f 3$ ).

Aunque las uniones matrimoniales de larga data son escasas en la Venezuela de hoy, es posible visualizar en las generaciones subsiguientes de hijos, nietos y bisnietos una tendencia a la conservación y defensa de algunos valores que se buscan sostener a pesar de los cambios histórico -contextuales. En ningún modo esto traduce que los jóvenes y adultos de este tiempo reproduzcan en su totalidad las formas de pensar y las prácticas de vida de sus padres o abuelos.

Procesos: amor, entendimiento y crisis. Amor, entendimiento y crisis se indican como procesos centrales de la interacción que configura la vida de la pareja y repercuten sobre la familia.

El amor es definido como un sentimiento vital, asociado al sentido y a la práctica de vida. Es además calificado como propulsor de las acciones humanas y sustento de la convivencia entre la pareja, con los hijos y otros parientes que forman la familia.

... el amor es un sentimiento ligado a la existencia misma ... la convivencia también es un caldo al cultivo del amor y es producto también del amor, porque si uno no quiere a la gente, no convive (Paulo, $-84^{a_{-}}$, f 3 ). 
... es lo que mueve al mundo, definitivamente, lo mueve y lo motiva y hace que este mundo pueda ser mejor (Rubén, -38 ${ }^{a_{-}, \text {f5). }}$

El entendimiento representa el acuerdo interno que fortalece el vínculo y el intercambio en la pareja. Implica para aquellos que han construido una práctica de convivencia tras varios años de unión, aceptar la diferencia, ser tolerante y evitar, en lo posible, la controversia como bases que ofrecen seguridad, solidez y permanencia a la relación.

... se trata de comprender, de entender la existencia, que vivir... no tiene por qué ser conflictivo, si uno acepta las limitaciones, que las tiene uno y las tiene también la persona de sus afectos, darse cuenta que es natural que las limitaciones existan y ponerte en la posición del que tiene un criterio distinto en un momento dado es una solución sabia, filosófica... Ella entiende perfectamente mis defectos que los tengo, desde luego, y yo entiendo los suyos y los comprendemos y nos lo toleramos (Paulo, $-84^{a_{-},}$f 3 ).

Yo creo que nosotros somos dos personas como muy sencillas, que no tenemos esas cosas de complicación, no somos de esa gente polémica, somos más o menos tranquilos, claro que no te puedo decir que algunas veces discutimos por alguna cosa... (Gabriela, $-75^{a_{-},}$f 3).

En algunos casos, cuando se trata de pareja homosexual, el entendimiento supone una convivencia afianzada en la validación socio-familiar que obtiene la pareja de su entorno inmediato.

... cuando comencé a pensar qué le daba estabilidad a mi relación de pareja, yo diría que la validación social de nuestra pareja, eso la hacía estable. El hecho de que no fuera una relación de pareja escondida o solamente entre nosotros y el grupo pequeño de amigos o un solo grupo, el grupo gay, sino que eso implicara hermana, sobrina, mamá, papá, qué sé yo, los tíos ... eso era reconocido por unos abiertamente, por otros por necesidad, no había manera de oponerse, sobretodo si el núcleo principal era tan abierto... (Félix, -49ª ${ }_{-}$, f 2).

El extremo opuesto de los procesos de interacción que definen la relación lo ocupa la crisis. Su origen puede ser diverso, también su resolución. Por lo general, las razones que explican la crisis se sitúan en oposición al entendimiento, el complemento o el amor.

... cuando ya se empieza a perder el respeto, cuando se empieza a perder la animación, cuando los puntos afines ya no siguen siendo los mismos, cuando uno de los dos se queda

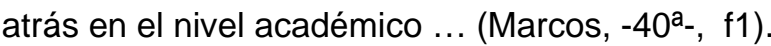

Una manifestación de la crisis la constituye la separación o disolución de la pareja y de la familia como unidad institucional. La ruptura del lazo afectivo entre la pareja marca una transición, generalmente dolorosa y de duración variable hasta lograr la evolución hacia un nuevo estado.

... yo me separé en el año 95 y yo estuve 8 años de barranco fuerte, como dicen por ahí, me pegó mucho, fue muy fuerte y yo me dediqué más a mi cosa de la maternidad, mi trabajo. No quería saber de la esfera afectiva, me dediqué más a la esfera más inmediata, a la que tenía que resolver, que era trabajar, más quedarme en mi casa (Laura, $-50^{a_{-}}$, f5).

Los hijos. Cuando se tienen, cuando no se pueden tener, incluso, cuando no se plantean como opción, los hijos forman parte de los discursos de hombres y mujeres cuando ellos se refieren a la familia. Las interpretaciones que los hombres y mujeres consultados elaboran alrededor de los hijos dan cuenta de sus aspiraciones, realidades y proyecciones. 
La presencia del hijo pareciera, a veces, estar relacionada con un reclamo social externo y con la necesidad de responder a él más que con una necesidad y/o deseo individual, sin embargo la exigencia propia de pertenecer a un grupo o el anticipar la ausencia de soporte de grupo lleva a pensar el hijo como necesario y a considerar, con la pareja, la decisión de tenerlo. Se aprecia también que el disponer de condiciones mínimas para decidir tener hijos es un requisito ineludible precisamente por que "el hijo" importa en tanto persona.

Cuando se tienen hijos se expresa la sensación de completud y logro de vida. El hijo adquiere el significado de razón de la existencia humana y raigambre de la continuidad.

... para mí fue importante, yo creo que yo me hubiera sentido muy incompleta si no hubiera tenidos hijos, era muy importante mis hijos, me sentiría como vacía sino tuviera hijos. Han llenado mi vida desde todo punto de vista, es que ha sido maravilloso ... los que tenemos hijos de alguna manera cumplimos con la biología ... con los hijos yo retomé también mi parte espiritual (Laura, $-50^{\mathrm{a}}-$, $f 5$ ).

... es lo más grande que puede tener uno, aparte de la madre, esa semillita que uno puede de alguna manera saber que viene, que es una parte de uno y que, bueno, va a ser esa personita que de alguna manera uno va a ir criando hasta que llegue a adulto y uno pueda decir "mira, ese es mi hijo" (Rubén, -38ª-, f5).

Frente a la limitación biológica para tener hijos se racionaliza que son una responsabilidad grande porque se le deben a la sociedad, a ella pertenecen. En tanto se plantee la sociedad como una sociedad mejor a la que se tiene y donde se participa, se necesita que ellos tengan protección, afecto y valores para que en su momento hagan expresión de ello. Estas reflexiones hacen suponer que existe demasiada carga sobre la decisión de tener los hijos o no tenerlos; sobre todo, porque los resultados de la crianza no son sólo responsabilidad y hechura de los padres, es un producto que se consolida o logra sus expresiones como consecuencia de múltiples factores incidentes.

A mí me parece que los hijos son una responsabilidad bárbara entre otras porque no te pertenecen, son personas que con suerte uno ayuda a crecer en términos de brindarles protección, ciertos parámetros vitales que me parecen importantes, ciertos valores, pero que llegado su momento ellos escriban las páginas de su vida como tienen a bien hacerlo, te guste o no te guste, independientemente que todo ese bagaje de afecto, de protección y de valores que le hayas podido dar, pues uno aspira que efectivamente influya en ellos, pero yo creo que es un ejercicio de responsabilidad muy grande ... (Rosa, $-35^{a_{-},}$f1).

Cuando los hijos no se plantean como una opción, porque se forma parte de una familia homosexual el tema de los hijos se presenta en un momento determinado de la vida del adulto, afianzado en la necesidad por la compañía y en los afectos compartidos. De hecho, en algunas familias homosexuales los hijos constituyen una presencia inevitable por diversas razones: porque ya forman parte de la historia previa de alguno de los miembros de la pareja, porque se decide sobre la adopción o porque se plantea tenerlos entre un hombre y una mujer homosexuales. En estas familias el valor de la paternidad y la maternidad cobran importancia por razones comunes a las familias heterosexuales: "criar hombres rectos o mujeres probas" más allá de su orientación sexual.

El valor de la paternidad, maternidad, con todo lo que eso implica: el cariño, esas cosas también como convencionales de criar hombres rectos o mujeres probas, igualito te lo da una pareja homosexual, y para uno ya se ha convertido en una cosa hasta cómica cuando dicen 
«bueno, pero cómo es posible que se vaya a criar un niño o una niña con homosexuales, ¿qué va a salir de allí?», yo digo, bueno, otra persona, porque yo gay salí de un matrimonio perfectamente heterosexual, entonces no es que un matrimonio o una pareja homosexual va a levantar a un niño o niña homosexual, pues viene la persona con lo que venga (Félix, -49a-, f 2).

En síntesis, la familia de destino, del porvenir o la nueva familia adquieren vida propia, diferente a la familia de origen, porque se plantea en los nuevos tiempos, anhelada desde el imaginario social. Esta familia enfrenta formas plurales que imprimen a su dinámica interior signos originales marcados por los rasgos de individualidad y por la convivencia que desarrollan sus miembros. Las parejas que no tienen hijos por decisión propia, no por problemas biológicos ni por homosexualidad, sino porque no entran en su proyecto de pareja, no tienen tal vez en nuestro país el incremento que muestran en países europeos; sin embargo, es una estructura que dice mucho de las transformaciones actuales de la familia, porque las parejas priorizan sobre los hijos su estabilidad económica, o su desarrollo personal o profesional.

\section{Familia y "la sociedad que pretendemos construir"}

El papel que tiene la familia en el desempeño social del individuo, junto a la presencia que ha venido tomando esta institución a través de la participación social que desarrollan sus miembros, permiten afirmar el vínculo insustituible, la ligazón sostenida y la interdependencia entre familia y sociedad. Así, por mayor distancia que se establezca entre la vida interna de la familia y la dinámica social, la interacción es inevitable.

\section{Papel de la familia en el desempeño social}

Sin lugar a dudas la familia representa, hoy como ayer, el referente de transformaciones personales y sociales. En este orden se constituye en la base para el desarrollo de valores como la tolerancia a la pluralidad de las formas. Sobre sus hombros descansa, por tradición, la práctica transmisiva e interactiva con la sociedad. A su vez, el papel del entorno social facilita o restringe la adaptación de nuevas formas de familia que se desarrollan y buscan posicionarse socialmente.

... yo creo que en el caso de una pareja del mismo sexo, por no decir solamente dos hombres, dos mujeres también, aportan lo que tengan que aportar como aporta cualquier otro a la sociedad, en lo intelectual... Yo creo que ni más ni menos que cualquier otra pareja ... ese hombre o mujer homosexual viene de los mismos valores, actitudes y creencias de esa misma sociedad y aportará aunque sea desde una pareja distinta lo que sea que haya venido aprendiendo también, a lo mejor se da que por las mismas circunstancias que haya podido vivir en algunos casos vaya aportando más tolerancia a la diversidad, pudiera ser, por las circunstancias, si es que decide ser, además, una pareja abierta (Félix, -49a

En el caso particular de la familia de clase media venezolana y de las expectativas que se colocan sobre ella, como gestora de la fuerza emergente que conduce y produce cambios para el país, se expresa la preocupación por su fragilidad. Imprecisión, inconsistencia son tal vez los calificativos que explican su estado actual y la convierten en una institución susceptible de las amenazas constantes que le impone el medio social. No es acaso esta manifestación, ¿un eco del temor a la inestabilidad que genera el tránsito hacia los cambios? Una respuesta posible a esta pregunta puede estar en las 
proyecciones que hacen las personas de su familia de origen a la familia que se construye. En ellas se procura repetir una realidad que se conoce y valora, sin prever los acomodos necesarios a los cambios sociohistóricos.

... creo que sí hay un brecha en los valores de la clase media y que al final por eso está siendo tan terriblemente vulnerable, yo creo que la clase media está generando niños que van a ser una élite, que se educan y otros niños que son niños con problemas, niños con problemas de conducta, niños con problemas de drogas, niños con problemas de alcohol, niños con otro tipo de problemas porque el afecto y el tiempo que se les dedica es diminuto ... (Rosa, -35a ${ }^{-}$, f1).

\section{Participación}

La interacción que se logra entre la familia y otras instituciones sociales ocurre fundamentalmente a través de la participación de sus miembros en escenarios públicos diversos, donde se reproducen maneras propias que se construyen en la familia. Quizás la participación de la mujer en el medio laboral es uno de los jalones más importantes que han logrado un impacto específico en el seno de la familia, en su rol de madre y esposa, en la crianza de los hijos y en el papel del padre. También, este desvelar de los actores con menor participación activa en el espacio público ha generado impactos en la esfera social, la familia comienza a estar presente en múltiples entornos colectivos, desde allí se difunde y proyecta en sus contenidos.

Un espacio inusual que se visualiza como el centro de participaciones renovadas lo constituye el mundo de la política, en él la mujer busca por hacerse parte. En su propio discurso y en el de algunos hombres se destaca la apertura y la disposición para incursionar en esta esfera, hasta hace poco privilegio casi exclusivo de los hombres. En ellas, esta disposición pareciera suponer la conquista de una nueva meta, que se afianza en la seguridad adquirida tras las últimas conquistas y en la valoración positiva que logra hacer de su desempeño en otros contextos En ellos, la apertura hacia la participación de la mujer en la política tiene su fundamento, también, en una valoración de los logros sociolaborales que ésta ha obtenido, así como en una evaluación de la poca eficacia de sus pares en el desempeño político y la necesidad de renovar este ejercicio con una participación que se aspira exitosa.

[participación de la mujer en la política] ... es efectiva y es necesaria, porque el campo político tiene como mucha testosterona y muchas veces es un campo que es tan difícil para la mujer pero que a la vez puede aportar tanto, de hecho lo hemos visto, mujeres que se debaten en la política y en las altas esferas, claro, pero como profesionales que han sido, han aportado y tienen mucho que aportar, yo creo que es vital que la mujer tenga mayor participación política a todos los niveles (Rubén, -38 ${ }^{\mathrm{a}}$-, f5).

\section{Proyecciones: el lugar común y la diferencia}

La adaptación requiere ser mutua. Al interior de la familia se necesita renovar las bases de la formación y de los aprendizajes iniciales para lograr fortalecerse como institución. Una institución con vida propia, el centro de prácticas sociales que se proyectan sobre el colectivo. Es claro que su logro demanda una adaptación a las exigencias y circunstancias actuales, construir este ajuste forma parte de la tensión constante en la cual participan las familias de hoy. 
Yo creo que la familia tiene que ir adecuándose a formar individuos más adecuados para interactuar con su momento sin perder sus valores y creo que esa no es una elección muy fácil, creo que las familias en nuestra sociedad están educando a sus hijos y a sus hijas para una sociedad que ya no existe ... (Rosa, $-35^{a_{-},}$f1).

Probablemente la añoranza por los viejos tiempos se constituye en un punto de afianzamiento que impide avanzar en la aceptación de nuevas expresiones. Sin duda se transita por terrenos desconocidos e inexplorados, marchar sobre ellos requiere un punto de seguridad que ayude a mantener el equilibrio. Tener claro que estas bases pueden ser provisorias es la encrucijada que permitirá avanzar en la construcción de nuevas plataformas ajustadas a nacientes realidades.

... a mí una de las cosas que a veces me sorprende con mis amigos que tiene niños es que hacen la excelente planificación de que los muchachos hagan treinta actividades extracurriculares, pero no sé cuanto tiempo dedican a enseñarlos a ser buenas personas y enseñarlos a tener conciencia del otro, sobretodo en un país tan fragmentado como este y no me refiero sólo al rollo político, me refiero a un país donde la gente es rica, un pedacito es clase media y el resto es pobre... (Rosa, $-35^{a_{-},}$f1).

En síntesis, las familias de clase media se proyectan en un mañana impreciso, desde una actitud que no es ajena a los temores. Preocupa fundamentalmente ¿qué sociedad esperamos para nuestros hijos?, ¿cuál sociedad estamos construyendo desde ya?, ¿cómo los visualizamos en familia?, ¿qué huellas conservarán de la nuestra?, ¿qué rumbo tomarán sus vidas y que aportarán al colectivo?

\section{Conclusiones}

El marco de las dimensiones de este estudio se ubica en la aproximación inicial a las vivencias de venezolanos sobre la familia, los significados asociados a la familia compartidos por sus miembros, con énfasis en la significación construida por los propios actores sociales, así como la importancia que tiene la estructura narrativa de las historias con las que los actores construyen y se explican su realidad. Desde estos límites puedo concluir que los aportes suministrados por los informantes permiten un primer acercamiento y sugieren líneas de investigación que podré abordar críticamente en lo subsiguiente.

Los resultados comentados previamente son referidos única y exclusivamente a las familias con las cuales se trabajó, en ningún momento se ha pretendido hablar de y por «la familia venezolana» a partir de estos casos, sin embargo, en ellos es posible destacar elementos afines con los señalamientos de algunos autores (Beck, 2003; Beck y Beck, 2001; Guiddens, 2000 y Vidal, 2003). La realidad de las familias convocadas a esta discusión muestra las señales propias del proceso de transformación que se experimenta respecto de su estructura, constitución, sostenimiento en el tiempo, fundamentos de las crisis que enfrenta y riesgos previsibles. Algunos de los relatos recogidos son también una manifestación de la aprensión y la alarma que produce vivir y decidir sobre la diferencia y la varibilidad constante que caracterizan los nuevos tiempos.

En esta transición resultan notorios los cambios que acontecen entre hombres y mujeres y en la pareja (Sharim, 2005; Viveros, 2000); los niveles de profesionalización de la mujer, su participación en el mundo socio-laboral; las adaptaciones progresivas del rol masculino en la familia y las repercusiones que esto tiene sobre la dinámica familiar (Beck, 2003; Capriles, 2000, De Viana, 2000, 
Recagno-Puente, 2002). Muestra además tres dilemas que enfrentan las familias de estos tiempos: la presencia y/o postergación de la llegada de los hijos; la preocupación por su formación; y el esfuerzo que supone mantener para sí y para los hijos un nivel de vida aceptable; la conciencia de las amenazas que existen para las nuevas generaciones (Beck, 200; 2002).

De forma complementaria a las conclusiones obtenidas por algunos autores (Catalán, 2004), respecto a los acomodos de los diferentes roles entre los miembros de la pareja, en las familias de este estudio se añade la ocupación activa de la pareja en el sostenimiento / incremento del nivel de vida, lo cual demanda una actividad intensa fuera de la familia e impulsa a la postergación de la llegada de los hijos, al menos hasta asegurar una estabilidad para su crianza y desarrollo o a la designación de su cuidado en manos de los abuelos o de instituciones educativas. A juicio de la mayoría de las personas consultadas, la situación de inestabilidad socioeconómica y política actual en el país tiene un fuerte peso en estas decisiones.

\section{La interpretación de la familia}

Las personas interpretan a la familia con recursos de la historia personal, las prácticas sociales que se desarrollan en su contexto y los principios que las rigen. Los significados que se construyen de la interacción de estos elementos se transfieren a otros contextos sociales, modos y experiencias de vida.

La estructura de la familia nuclear compite con las situaciones de ruptura, la flexibilidad y temporalidad de las uniones que se observan en las nuevas familias así como con la diversidad de estructuras familiares. Las parejas que profesan la religión de manera activa y aquellas que han mantenido la unión matrimonial durante varios años son quienes sostienen invariablemente valores y principios de protección para la estructura nuclear, considerada indispensable en la crianza de los hijos y en el equilibrio social. Tal vez la posición conservadora adoptada por algunas de estas familias responda a su condición de católicos activos. Con esta exploración de la perspectiva a partir de la variedad de estructuras familiares, se plantea como tema interesente de investigación avanzar en la exploración sobre una diversidad marcada por la pertenencia familiar a diferentes credos religiosos.

Hombres y mujeres centran su atención particular en la construcción de las nuevas familias. Los hijos son producto del acuerdo, de una decisión que compete a la pareja, tras una minuciosa evaluación de las condiciones para garantizar al hijo un estado permanente de bienestar. Las expectativas sobre los hijos y nietos van especialmente dirigidas a representar y resguardar los valores de la familia y proyectarlos en el contexto social, tal y como ellos intentan hacerlo y en su momento lo realizaron sus propios padres. Este acuerdo intrafamiliar se distingue de la generación anterior, en el énfasis en la profesionalización de las hijas y su participación activa dentro del mundo social. Las expectativas sobre la familia que conformarán los adolescentes de hoy ameritan de una exploración mayor.

\section{Origen de los significados compartidos}

La familia como comunidad discursiva sostiene las variaciones de su dinámica interior y de su estructura en la temporalidad de los acuerdos, en las negociaciones que imponen las coyunturas o situaciones específicas que se enfrentan. A través del discurso se crean y modifican las realidades individuales y colectivas que atañen al grupo familiar, se enfrenta y se decide, se innova, organiza y 
construye, también, se deshacen las relaciones. La familia, de igual forma, es un contexto donde se producen disensos y se definen posiciones particulares.

La forma como los miembros de un mismo grupo familiar interpretan la realidad, en líneas generales, repite esquemas de significados que son comunes a la generación de sus padres. Hay remembranza del estado de cosas que definían a su familia de origen y que hoy sienten amenazadas, particularmente su estructura. Sólo los más jóvenes (adolescentes y adultos jóvenes) muestran mayor tolerancia y convicción frente a los cambios producto de las trasformaciones sociales.

Las personas, cuando narran sus experiencias familiares lo hacen a través de relatos reflexivos, anticipan el juicio o la pauta social y los contenidos están claramente marcados por este hecho. Al referir eventos de su vida destacan el contexto y la división temporal, mantienen una secuencia en su relato y pueden llegar a referir abundantes detalles explicativos cuando se trata de justificar su diferencia o similitud respecto del colectivo al cual pertenecen. Los disensos parecieran resolverse a partir del acuerdo interno que establecen los miembros y se regula o evita su comentario con personas ajenas al grupo familiar, o pertenecientes a la familia extensa.

El manejo de la secuencia histórica en las vidas de los miembros de estas familias presenta una referencia central al pasado para planificar el futuro. En estas historias se anticipan los peligros futuros tomando como medida eventos del pasado mediato o inmediato, de esta forma se aspira a tener el control y minimizar los incidentes imprevistos. En ninguno de los grupos familiares las proyecciones y construcciones hacia el futuro buscan oponerse al pasado, por el contrario, es fundamentalmente el pasado y los aprendizajes que él deja, así como los logros del presente concreto, los que sirven de punto de anclaje para planificar el futuro, esta situación es totalmente diferente en familias venezolanas pertenecientes al sector popular ("Autor/a", 2003; "Autor/a", Cristina Otálora e lleana Recagno-puente, 2006). Para los miembros pertenecientes a familias de este sector el presente es el tiempo central, el pasado es la ocurrencia remota que no tiene repercusión sobre los hechos y acciones subsiguientes, el futuro no demanda de anticipaciones ni previsiones.

El estudio de la familia nos plantea en la actualidad retos para su comprensión y para actualizar las prácticas de intervención que realizamos en las ciencias sociales. Es por ello que la investigación y la intervención que se hagan alrededor de ella deben permitir trazar la ruta más adecuada que reconozca lo cotidiano de su existencia.

Pensar en la sociedad que a diario construimos supone también considerar el espacio amplio de la discusión y la participación que requieren las múltiples formas que adopta la familia actual. En este sentido, la política de estado deberá considerar a la familia en su diversidad.

En la familia, la «democracia de la vida cotidiana» es un tema que reclama de una exploración más cercana y detenida. Es también un campo para el estudio de las relaciones de género y para la práctica interpretativa, tarea que con responsable afición epistemológica asumimos desde la Psicología. 


\section{Referencias}

Banister, Peter; Burman, Erica; Parker, Ian; Taylor, Maye y Tindall, Carol (1994). Métodos cualitativos en psicología. Guadalajara: Centro Universitario de Ciencias de la Salud. 2004.

Beck, Elizabeth (2003). La reinvención de la familia. En busca de nuevas formas de convivencia. Barcelona: Paidós.

Beck, Ulrich (2000). Retorno a la teoría de la «sociedad del riesgo». En Estudios Boletín de la A.G.E. NN 30, 7-20. Disponible en: http://age.ieg.csic.es/boletin/30/01.pdf [Consultado 04/04/07].

Beck, Ulrich (2002). La sociedad del riesgo global. Madrid, Siglo XXI. Disponible en: http://www.nodo50.org/dado/textosteoria/beck5.rtf [Consultado 26/03/07].

Beck, Ulrich y Beck, Elizabeth (2001). El normal caos del amor. Barcelona: Paidós.

Bruner, Jerome (1990). Actos de significado. Madrid: Alianza. 1991.

Bruner, Jerome (1986). Realidad mental y mundos posibles. Barcelona: Gedisa. 1998.

Capriles, Alex (2000). La familia en la sociedad de consumo. En Fundación Venezuela Positiva (ed.), Familia: un arte difícil (pp. 163-175). Caracas: Fundación Venezuela Positiva.

Catalán, Sarah (2004). Familias de dos profesionales: Características y manejo de un estilo familiar contemporáneo. Tesis de grado, Facultad de Humanidades y Educación, Universidad Central de Venezuela.

Ceballos, Esperanza y Rodrigo, María (2001). Las metas y estrategias de socialización entre padres e hijos. En: María, Rodrigo y Jesús, Palacios (coords.). Familia y desarrollo humano. (pp. 225243). Madrid: Alianza.

De Viana, Mikel (2000). La familia de fin de siglo XX en Venezuela: la perspectiva de los cambios. En Fundación Venezuela Positiva (ed.), Familia: un arte difícil (pp. 219-238). Caracas: Fundación Venezuela Positiva.

Flick, Uwe (2002). Introducción a la investigación cualitativa. Madrid: Morata. 2004.

Fundacredesa (1996). Estudio nacional de crecimiento y desarrollo humanos de la República de Venezuela. Proyecto Venezuela. Caracas: Fundación Centro de Estudios sobre Crecimiento y Desarrollo de la Población Venezolana - Fundacredesa.

Fundacredesa (2001). Indicadores de situación de vida. Movilidad Social años 1995-2001. Estudio nacional. Caracas: Fundación Centro de Estudios sobre Crecimiento y Desarrollo de la Población Venezolana - Fundacredesa.

Giddens, Anthony. (2000). Un mundo desbocado. Los efectos de la globalización en nuestras vidas. Santafé de Bogotá: Taurus.

Larrosa, Jorge. (1996). La experiencia de la lectura. Estudios sobre literatura y formación. Barcelona: Laertes. 
Marshall, Catherine y Rossman, Gretchen (1989). Designing qualitative research. Newbury Park: Sage.

Palacios, Jesús y María, Rodrigo (2001). La familia como contexto de desarrollo humano. En: María, Rodrigo y Jesús, Palacios (coords.). Familia y desarrollo humano, (pp. 25-44). Madrid: Alianza.

Recagno-Puente, Ileana (2002). Socialización de la adolescente: Género, vida cotidiana y embarazo adolescente en familias populares. En lleana Recagno-Puente (comp.), Educación y familia: proyecciones sociales y educativas, (pp.77-100). Caracas: Fondo editorial de la Universidad Central de Venezuela.

Sharim, Dariela (2005). La identidad de género en tiempos de cambio: una aproximación desde los relatos de vida. PSYKHE, Vol. 14, № 2, 19-32

Stake, Robert (1999). Investigación con estudio de casos. Madrid: Morata. 1998.

Strauss, Anselm y Corbin, Juliet (2002). Bases de la investigación cualitativa. Técnicas y procedimientos para desarrollar teoría fundamentada. Medellín: Universidad de Antioquia. 1998.

Taylor, Steven y Bogdan, Robert (1990). Introducción a los métodos cualitativos de investigación. Buenos Aires: Paidós. 1984.

Valles, Miguel (2000). Técnicas cualitativas de investigación social. Madrid: Síntesis.

Vidal, Fernando (2003). El devenir de la familia: una comunidad contractual, reflexiva y plural. En Sal terrae: Revista de teología pastoral, Tomo 91, № 1067, pp. 357-372.

Viveros, Mara (2000). Notas en torno a la categoría analítica de género. En Angela Robledo y Yolanda Puyana (comp.), Ética: masculinidades y feminidades (pp. 56-85). Colombia: Universidad Nacional de Colombia.

\section{Apéndice}

\section{Modelo de guión para la entrevista con ADULTOS DE ESTRATO MEDIO}

Proyecto: Género y vida familiar ... un estudio de significados

\section{Noción de Familia}

-¿Qué significa la familia?, ¿para qué le sirve la familia a las personas?, ¿para qué le sirve a la sociedad?

-En la familia ¿cuáles son las funciones de: padre, madre, hijos, abuelos?

-¿Qué piensas tú de la familia?

-¿Quiénes forman tu familia?

- ¿Cómo ves a tu familia dentro de unos años? 
¿¿Qué valor tiene la familia para tu pareja / tus hijos?

\section{Funciones afectivas y de conyugalidad -Pareja-}

-¿Qué significa para ti la pareja?

-En la relación de pareja ¿qué papel tiene la mujer/ el hombre?

-¿Cuál debe ser el papel de la mujer/hombre en la selección de la pareja y en la conquista?

-¿Qué te ha llevado a formar pareja?

-Para la constitución de la pareja ¿qué importancia tiene para ti casarse?, ¿qué ganaste y qué perdiste al formar pareja?, ¿crees que es lo mismo para tu pareja?

-Si pudieras cambiar algo en tu relación de pareja ¿qué cambiarías?

-¿Por qué crees que es importante la figura masculina/femenina en el hogar?

-¿Qué esperas de tu pareja en la relación que llevan?

-¿Qué piensas acerca de la infidelidad?, ¿crees que la infidelidad es lo mismo para la mujer que para el hombre?

-¿Qué es para ti el amor?

-¿Cuál es el papel que juegan los hijos en la relación/ mantenimiento de la pareja?

- ¿Cómo describirías la relación de pareja de tus padres?

-¿Qué mantiene a una pareja por largo tiempo? Abuelos-

\section{Divorcio / Separación / Abandono}

-¿Qué es para ti el divorcio y la separación?

-¿Qué crees tú que lleva a una pareja a separarse?

-Cuando ocurre la separación ¿qué hace generalmente el hombre y qué hace generalmente la mujer?

-Cuando uno de los cónyuges deja al otro ¿cómo se enfrenta la soledad?, ¿qué pasa con los hijos?, ¿cómo se asume la crianza?

-¿Quien lleva el control de la natalidad en una relación?

-¿Qué piensas de la esterilización de las mujeres y de los hombres?

\section{Hijos}

-¿Qué significa un hijo / los hijos?

-¿Qué significa para ti tener una niña?, ¿un niño?

¿Cuál es el momento ideal para un hombre y para una mujer tener un hijo?, ¿cuál es el número de hijos más conveniente en esta época frente a lo deseado?

¿¿Qué esperas de tu hijo/a en relación contigo?

-¿Qué papel han jugado tus hijos en tu vida?

-¿Qué esperas de tus hijos / hijas cuando sean mayores?, ¿qué haces (has hecho - harás) para lograrlo?

-¿Cuándo consideras tú que un hijo se hace hombre y cuándo que una hija se hace mujer?

-¿Qué pensarías y qué harías si un hijo (a) tuyo fuera homosexual (preferencias sexuales por personas de su mismo género)?

-¿Qué le dirías a tu hijo (a) el día que decida vivir en pareja? 
-¿Qué significan los hijos para tu pareja?

-¿Cómo ves la relación que lleva tu pareja con los hijos (los de la pareja, los de otras uniones)?

- ¿Es diferente la relación que tu pareja establece con los hijos y con las hijas? (explorar los aspectos que ellos mencionan)

-¿Cómo es la crianza de los hijos de la pareja que no son hijos comunes de la relación?

-¿Qué significa la figura del padrastro/madrastra para los/las hijos/hijas?, ¿cómo se da la relación entre ellos?

\section{PAREJAS SIN HIJOS}

-La decisión de tener hijos ¿de quién depende?

-La importancia del hijo en la vida de las personas, de las parejas y de la familia.

-¿Qué supone la imposibilidad biológica de tener hijos?, ¿qué repercusiones tiene en la vida de las personas, de las parejas y de la familia?

-iQué significa la adopción en la vida de las personas, de las parejas y de la familia?

-La adopción es una opción ¿para qué?, ¿cómo es la vivencia de la maternidad / paternidad con un hijo/a adoptado/a?

-¿Cuáles son las repercusiones de la adopción dentro de la dinámica familiar y social?

-Las dificultades y las vías para la adopción

-No tener hijos ¿una decisión / una opción en la vida de las personas, de las parejas y de las familias?

\section{Relación entre hermanos}

-¿Cómo se llevan tus hijos entre ellos? (destacar las diferencias y sus razones)

- ¿Cuál es la función de los hijos varones en la relación con sus hermanas? y ¿cuál la función de las hijas con respecto a sus hermanos?

-¿Cómo manejas la relación entre los hermanos que no son hijos comunes de la pareja? (relaciones de poder)

\section{Funciones de cuidado y socialización}

-¿Qué significa la crianza de los hijos?

-¿Cómo se educa a un hombre? y ¿cómo se educa a una mujer?

-¿Cómo te ha parecido la tarea de criar y educar a tus hijos?

-¿Cómo reaccionan tus hijos frente a la normas del hogar?, ¿cómo lo hace tu esposa / esposo?

-¿Cómo te pareció la forma en que te criaron?

-¿Cómo te parece la forma en que llevó la familia tu papá / tu mamá?

-¿Qué haces tú o tu pareja cuando los hijos cometen una falta?

- ¿Hay alguna diferencia entre los hijos y las hijas en cuanto al manejo de las normas?, (castigo, tolerancia ante las faltas, cigarrillos, salidas, alcohol).

-¿Cómo asumes la iniciación sexual y el ejercicio de la sexualidad de tus hijos e hijas?, ¿hay algunos temores al respecto?

-¿Cómo se maneja el embarazo adolescente en esta familia?

\section{Funciones de ocio y recreación}


¿Qué hace generalmente tu familia un día de descanso?, ¿qué actividades se comparten?

¿Cómo te diviertes con tus hijos?, ¿cómo lo haces con tus hijas? (Adolescentes)

¿Cómo se celebra el día del padre, el día de la madre y otras fechas como la navidad?

\section{Maltrato y violencia}

-¿Qué significa para ti el maltrato en la vida en familia?

-¿Cuál es el manejo que le da tu familia a la violencia en el hogar?

- ¿Sientes que alguna vez te has sobrepasado con el castigo que le das a tu hijo/a adolescente?

- ¿Cómo preparas a tus hijos/hijas para evitar/responder al maltrato dentro y fuera de la casa? (para que no se dejen maltratar)

-¿Qué opinas de los hombres que maltratan de palabra y físicamente a sus mujeres?

-¿Cómo crees que la mujer puede maltratar al hombre?

\section{Economía doméstica}

-¿Cómo evalúas el trabajo de la mujer en la calle? Ventajas y desventajas.

-¿Qué significa para ti que la madre asuma sola el mantenimiento del hogar?

-¿Cómo se maneja la economía en tu hogar?, ¿cómo se distribuyen los gastos?

-¿Qué valores se manejan en tu familia alrededor del dinero y en qué se invierte?

\section{Trabajo doméstico}

-¿Cómo se distribuye en la familia las tareas del hogar?, ¿ha variado en el tiempo?

- ¿Cuál de las tareas del hogar te parece que es la más pesada?, ¿quiénes participan en la realización de esa tarea?, ¿cuáles tareas del hogar realizas sólo tú? ¿qué crees de esto?

-¿Qué crees que piensa tu esposo de su participación en la realización de tareas del hogar?

\section{Valores familiares}

¿Qué sucesos más importantes han marcado tu vida en familia? (con la pareja, con los hijos)

¿Qué es lo más importante para tu familia? ¿Qué se rechaza en tu familia?

¿Qué tipo de enseñanzas/costumbres sobre la familia (que recibiste en tu casa) se repiten en la forma de llevar tu hogar y en la crianza de tus hijos?

\section{Relación con el espacio público}

-¿Qué crees que tiene en común la vida de las mujeres/hombres de tu clase, de tu grupo?

-¿En qué espacios públicos participa tu familia?, ¿cuáles son las ventajas y desventajas de esa participación?

-¿Cómo participa tu familia de la vida en esta comunidad?

-¿Cómo funciona la relación entre los vecinos?, ¿qué aspectos de tu vida familiar crees que compartes con tus vecinos y otros miembros de esta comunidad?

- ¿Cómo evalúas la participación actual de la mujer en la política?, ¿cómo crees que la avalúa el hombre?

\section{Hacerse madre - maternidad}


-¿Qué es ser madre?

-¿Qué sentiste cuando saliste embarazada por primera vez?, ¿qué sentiste cuando nació tu primer hijo?

- ¿A qué edad crees que se debe tener el primer hijo?, en el caso de los hombres y de las mujeres -¿Cómo sientes a tus nietos?, ¿qué estás dispuesta a hacer por ellos?, ¿cómo ha sido con los hijos? -¿Qué opinas del aborto como opción para evitar tener hijos no deseados?

\section{Feminidad}

-¿Qué es para ti lo femenino?, ¿cómo vives tú lo femenino?

¿¿Qué es ser mujer desde lo femenino?

-¿Cómo se expresa eso de ser mujer?, ¿frente a la pareja cómo eres tú mujer?

-¿Cómo crees tú que el hombre ve lo femenino?

-¿Cuáles son las ventajas de ser mujer? y ¿cuáles son las desventajas?, ¿qué crees que piensan los hombres sobre eso?

-De lo femenino ¿qué has sacado de tu mamá?, ¿que no te gustaría repetir de ella? y ¿qué te hubiera gustado que ella te enseñara?

-¿Qué te gustaría que tu hija repitiera de ti (de lo que a ti te haya funcionado)?

-¿Qué cosas hay que no puedas hacer por el hecho de ser mujer?, ¿qué crees tú que los demás no le deberían prohibir a las mujeres?

-¿Qué significa la regla en la vida de la mujer?, cuándo la regla desaparece ¿cómo influye esto en la vida de la mujer?, ¿qué significados puede tener para el hombre?

\section{Hacerse padre - paternidad}

-¿Qué es ser padre?

-¿Cómo te sentiste cuando nació tu primer hijo?

-¿Qué te gustaría que tu hijo repitiera de ti (de lo que a ti te haya funcionado)?

-¿Qué significa para un hombre no poder tener hijos?

-¿Qué opinas del aborto como opción para evitar tener hijos no deseados?

\section{Masculinidad}

¿¿Qué es para ti lo masculino?

-¿Qué es para ti ser hombre?

-¿Cómo se expresa eso de ser hombre?

-¿Qué crees tú que significa para la mujer lo masculino?

-¿Tú crees que tu hijo es más hombre por el hecho de que tenga muchas relaciones sexuales?, ¿qué otras cosas hacen a un hijo tuyo más hombre?, ¿tú haces algo para que tus hijos sean más hombres?

-¿Qué cosas hay que no puedas hacer por el hecho de ser hombre?, ¿qué crees tú que los demás no le deberían prohibir a los hombres? 


\section{Historia editorial}

Recibido: 04/10/2006

Primera revisión: 10/04/2007

Aceptado: 27/04/2007

\section{Formato de citación}

Mora, Leonor. (2007). La familia en la sociedad de hoy. Vivencias de venezolanos de clase media. Athenea Digital, 11, 56-82. Disponible en http://psicologiasocial.uab.es/athenea/index.php/atheneaDigital/article/view/365/326.

Leonor Mora Salas. Psicóloga Social y Psicóloga del Desarrollo. Docente-Investigadora del Instituto de Psicología de la Universidad Central de Venezuela. Profesora de postgrado en las áreas de Metodología de la Investigación y Evaluación de Proyectos Sociales. Líneas de trabajo: familia; lenguaje e interpretación (lectura, escritura, narrativa y métodos cualitativos de investigación).

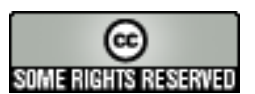

Este texto está protegido por una licencia Creative Commons.

Usted es libre de copiar, distribuir y comunicar públicamente la obra bajo las siguientes condiciones:

Reconocimiento: Debe reconocer y citar al autor original.

No comercial. No puede utilizar esta obra para fines comerciales.

Sin obras derivadas. No se puede alterar, transformar, o generar una obra derivada a partir de esta obra.

\section{$\underline{\text { Resumen de licencia }}$}

$\underline{\text { Texto completo de la licencia }}$ 